\title{
Inhibition of TLR8- and TLR4-induced Type I IFN induction by alcohol is different from its effects on inflammatory cytokine production in monocytes
}

\author{
Maoyin Pang ${ }^{1,2+}$, Shashi Bala ${ }^{1+}$, Karen Kodys ${ }^{1}$, Donna Catalano ${ }^{1}$ and Gyongyi Szabo ${ }^{1 *}$
}

\begin{abstract}
Background: Prolonged alcohol consumption is a significant co-factor in the progression of chronic viral infections including hepatitis $C$ and HIV, which are both single-stranded RNA viruses. Toll like receptor 8 (TLR8), a pattern recognition receptor expressed in monocytes, senses viral single stranded RNA as a danger signal and leads to the induction of Type I interferon (IFN) as well as the pro-inflammatory cytokine, tumor necrosis factor alpha (TNF alpha). Lipopolysaccharide (LPS), a Toll like receptor 4 (TLR4) ligand, was shown to affect inflammatory cell activation after alcohol consumption and in HIV and HCV infections. Here we hypothesized that alcohol exposure modulates TLR8- and TLR4-ligand-induced monocyte activation and affects both type I IFN and inflammatory cytokine induction.

Results: The TLR8 ligand, CL075, as well as the TLR4 ligand, LPS, resulted in a significant induction of TNF alpha both at the mRNA and protein levels in human monocytes. We found that both acute and prolonged alcohol treatment resulted in inhibition of type I IFN induction by either TLR8 or TLR4 ligands in human monocytes at the protein and mRNA levels. In contrast to Type I IFN production, the effects of acute and prolonged alcohol were different on inflammatory cytokine activation after TLR8 or TLR4 ligand stimulation. Acute alcohol inhibited TLR8or TLR4-induced TNF alpha protein and mRNA induction while it augmented IL-10 production in monocytes. In contrast, prolonged alcohol treatment augmented TNF alpha without affecting IL-10 production significantly in response to either TLR8 or TLR4 ligand stimulation.

Conclusions: These novel results suggest first, that alcohol has a profound inhibitory effect on Type I IFN induction regardless of intracellular (TLR8) or cell surface-derived (TLR4) danger signals. Second, both acute and prolonged alcohol exposure can inhibit antiviral Type I IFN pathway activation. Third, the opposite effects of acute (inhibitory) and prolonged alcohol (augmentation) treatment on pro-inflammatory cytokine activation extend to TLR8-induced signals beyond the previously shown TLR4/LPS pathway.
\end{abstract}

Keywords: Acute, chronic, alcohol, IFN $\beta$ ? $\beta$ ?, IL-10, TNF alpha

\section{Background}

The immunoregulatory effects of acute and chronic alcohol use have been linked to negative clinical outcomes including prolonged recovery after trauma or burn injury, elective surgery, liver disease and infections

\footnotetext{
* Correspondence: gyongyi.szabo@umassmed.edu

† Contributed equally

'Department of Medicine, University of Massachusetts Medical School, 364

Plantation Street, Worcester, MA 01605, USA

Full list of author information is available at the end of the article
}

[1-4]. Excessive alcohol consumption was also identified as an independent risk factor in hepatitis $\mathrm{C}$ virus $(\mathrm{HCV})$ infection that leads to chronic infection in up to $80 \%$ of cases [5,6]. Excessive alcohol use also affects outcomes in HIV infection and predisposes to advanced disease $[7,8]$. Both HCV and HIV are single-stranded RNA viruses that induce anti-viral innate immune responses via host pathways that recognize the viral "danger signals" [9-11]. Toll-like receptor 8 (TLR8) can sense 
single-stranded RNA from both HIV and HCV viruses and triggers downstream signaling to induce production of Type I IFNs and pro-inflammatory cytokines [12-14]. TLR8 is expressed in monocytes and macrophages and it is localized intracellularly in the endosomes where it is positioned to be expose to viral danger signals [15].

Limited numbers of previous studies evaluated the effects of alcohol on virus-induced immune responses and mostly showed decreased antiviral immune responses [4,16-18]. In hepatoma cells, alcohol was shown to affect innate antiviral pathways and increase HCV replication in human liver cells [19]. The effects of alcohol exposure on anti-viral immune responses are yet to be delineated in human immune cells that contribute to the production of both Type I IFNs and inflammatory cytokines [9].

In addition to viral danger signals, gut-derived lipopolysaccharide (LPS), a ligand of Toll like receptor 4 (TLR4), has been shown to play a role in HIV and HCV infection as well as in complications of chronic alcohol exposure [20-22]. It has been shown that serum/plasma LPS levels are elevated in patients with untreated HIV infection and a moderate increase in serum LPS was also reported in patients with chronic HCV infection $[23,24]$. It has been postulated that the source of the circulating LPS is the gut due to increased gut permeability [23]. Increased gut permeability and an increase in circulating LPS levels are the central components in the pathogenesis of alcoholic hepatitis [25,26]. Thus, LPS/ TLR4 stimulation has direct clinical relevance to HIV and $\mathrm{HCV}$ as well as alcohol consumption.

The effects of alcohol on LPS/TLR4 signaling were evaluated in numerous previous studies, however, the effects of alcohol on TLR4-induced IFN responses are yet to be defined. Here, we tested the hypothesis that acute and prolonged alcohol exposures modulate proinflammatory cytokines as well as Type I IFN induction in response to TLR8 or TLR4 ligand stimulation.

\section{Results}

TLR8- and TLR4-induced Type I IFN production is inhibited by acute and prolonged alcohol treatment in human monocytes

Innate immune responses by circulating monocytes and tissue macrophages are triggered by viral and bacterial danger signals to induce Type I IFNs and inflammatory cascade activation $[4,17]$. TLR8, expressed in the endosome senses single-stranded RNA while TLR4, expressed on the cell membrane is activated by bacterial lipopolysaccharide [27]. Here we tested the hypothesis that alcohol interferes with Type I IFN production in response to viral or bacterial pathogen-derived signals. Human peripheral blood monocytes were stimulated with a TLR 8 or TLR4 ligand in the presence or absence of $25 \mathrm{mM}$ alcohol. This in vitro treatment represents acute alcohol exposure in humans as $25 \mathrm{mM}$ alcohol approximates $0.1 \mathrm{~g} / \mathrm{dl}$ blood alcohol level often found after consumption of 4-5 drinks in non-alcoholic individuals [28]. Monocyte stimulation with CL075 (TLR8 ligand) or LPS (TLR4 ligand) resulted in a significant increase in IFN $\beta$ production at 6 hours after stimulation while alcohol treatment alone did not affect baseline IFN $\beta$ production (Figure 1). Acute alcohol treatment during the TLR8 and TLR4 stimulation resulted in a decreasing trend in IFN $\beta$ production in monocytes but this did not reach statistical significance (Figure 1).

Considering that chronic alcohol consumption in humans often involves sustained alcohol exposure, we next evaluated the effects of prolonged alcohol treatment on IFN $\beta$ production. Monocytes were exposed to $25 \mathrm{mM}$ alcohol for 7 days followed by TLR 8 and TLR4 ligand stimulation. The alcohol concentration in the supernatant was measured using the Analox Alcohol Analyzer (Analox Instruments) and ranged from $23 \mathrm{mM}$ to $21 \mathrm{mM}$ over the 7 -day period (Additional file 1, Table S1). This result is in accordance with our previous study where we reported that alcohol concentrations vary between 24 to $20 \mathrm{mM}$ [28]. To rule out the possibility that prolonged alcohol treatment has any adverse effect on cell viability, we performed an MTT assay (Promega) and found no difference in the viability of alcohol -naïve and -treated cells as shown in Additional file 2, Figure S1. Recently, it has been shown that alcohol $(25 \mathrm{mM})$ does not influence the human peripheral

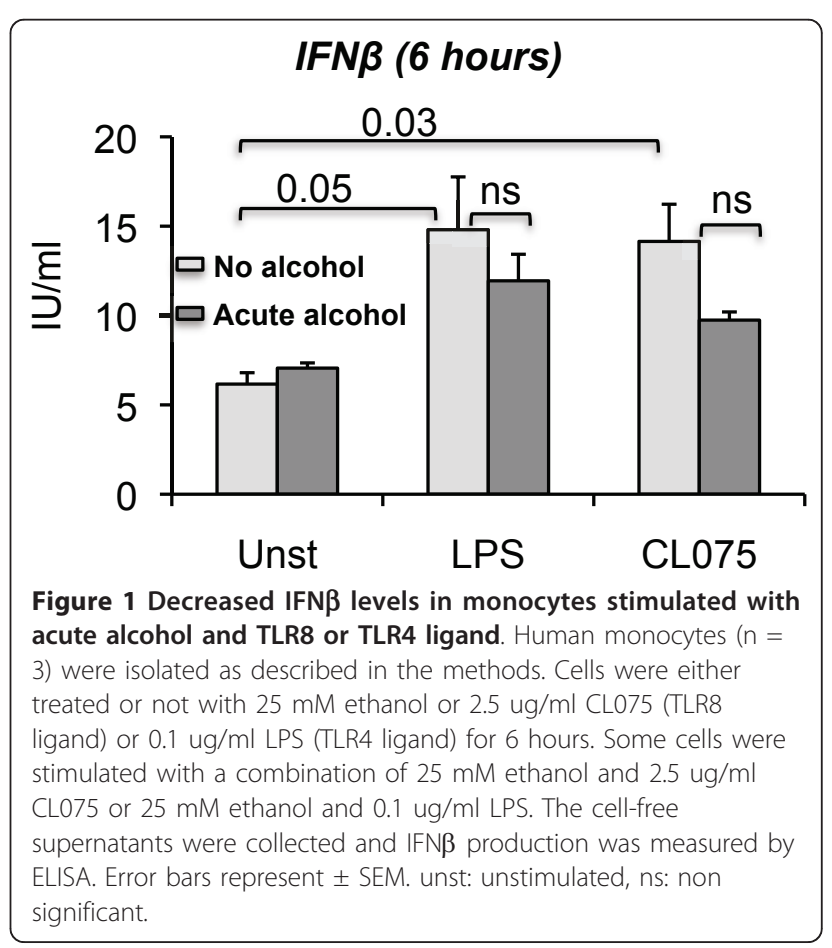


mononuclear cells viability when either incubated for 24 hours or 48 hours and our results support this finding [29].

Here we found that prolonged alcohol treatment alone did not have any affect on baseline IFN $\beta$ production (Figure 2A and 2B). However, we found significant attenuation of both TLR8- and TLR4-induced IFN $\beta$ production in prolonged alcohol-treated monocytes at 6 hours (Figure 2A). Inhibition of IFN $\beta$ production was sustained in TLR4-stimulated cells even after 24 hours (Figure 2B). These data suggested that in the presence of prolonged alcohol treatment, IFN $\beta$ production is decreased in monocytes whether induced by TLR 8 or TLR4 stimulation. To further assess the mechanisms of alcohol-induced inhibition of IFN $\beta$ production, we evaluated the mRNA levels of IFN $\beta$ and found that both TLR 8 and TLR4-induced IFN $\beta$ mRNA levels were decreased in monocytes after prolonged alcohol treatment (Figure 2C). These data suggested that prolonged alcohol treatment inhibits type I IFN induction via TLR 8 or TLR4 mediated pathways and affects IFN $\beta$ mRNA levels. We also evaluated the affect of alcohol on TLR8 (CL075) and TLR4 (LPS) receptors and found no significant differences in alcohol-exposed cells ( 1 or 7 days) both at mRNA (data not shown) or protein levels (Additional file 3, Table S2). This was consistent with our previous finding where we showed that alcohol has no effect on TLR4 expression [28]. This data indicates that alcohol doesn't interfere with receptor expression but might exert its effects on downstream signaling pathways.

\section{Induction of TNF alpha via TLR8 or TLR4 stimulation is inhibited by acute but enhanced by prolonged alcohol treatment}

Blood monocytes contribute to systemic immune responses and represent the source of inflammatory cells recruited to different tissue sites. Here we tested the hypothesis that acute and chronic alcohol regulates the monocyte cytokine production profile in response to TLR 8 or TLR4 stimulation. Both LPS, a TLR4 ligand, and CL075, a TLR8 ligand, induced production of the pro-inflammatory cytokine TNF alpha in monocytes isolated from healthy volunteers (Figure 3). We found that co-administration of alcohol as an acute alcohol challenge with TLR8 or TLR4 ligand resulted in a significant inhibition of TNF alpha production (Figure 3). This was consistent with previous studies from our and other laboratories on inhibition of LPS-induced TNF alpha induction by acute alcohol both in vitro and in vivo [28,30-32].

Next, monocytes were exposed to alcohol for 7 days at a physiologically relevant concentration $(25 \mathrm{mM})$, which had no adverse effects on cell viability (Additional file 2,
Figure S1). Chronic alcohol treatment alone induced minimal but statistically significant TNF alpha production and robust TNF alpha production was elicited at 6 or 24 hours by TLR8 or TLR4 stimulation (Figure 4A and $4 \mathrm{~B})$. In contrast to the effects of acute alcohol, prolonged alcohol treatment significantly augmented both TLR8 and TLR4-induced production of TNF alpha in human monocytes (Figure 4A and 4B). The increase in TNF alpha protein was mirrored by the mRNA upregulation in monocytes after 7 days of alcohol treatment in response to TLR8 or TLR4 stimulation compared to alcohol naïve cells (Figure 4C).

The anti-inflammatory cytokine, IL-10, is increased by acute alcohol in response to TLR8 or TLR4 stimulation Pro-inflammatory cytokine production, such as TNF alpha, is counterbalanced by IL-10 induction, an antiinflammatory cytokine in monocytes [33]. Here we found that acute alcohol treatment significantly upregulated TLR8 and TLR4-induced IL-10 production in human monocytes (Figure 5). The increased IL-10 production in acute alcohol exposed monocytes was consistent with the attenuation of TLR8 and TLR4-induced TNF alpha production (Figure 3 ). This result suggests the role of IL-10 in the attenuation of TLR8- or TLR4induced TNF alpha after acute alcohol treatment. Finally, we assessed IL-10 production after prolonged alcohol treatment. While there was a slight tendency for increases in IL-10, there was no significant change in TLR8 or TLR4-induced IL-10 production at the protein (Figure 6A and 6B) or mRNA levels (Figure 6C) in alcohol treated cells.

\section{Discussion}

The immunomodulatory effects of alcohol use have been described in various clinical settings including bacterial and viral infections as well as in post-trauma and postsurgical recoveries [2-4,34]. Increased activation of the inflammatory cascade was found in chronic alcoholics with liver disease where blood monocytes produced increased levels of the pro-inflammatory cytokine TNF alpha $[35,36]$. While inflammatory cytokine activation has been investigated in several conditions related to alcohol consumption, little is known about the effects of alcohol on the induction of anti-viral immune mediators.

In this study, we investigated the effects of acute and prolonged alcohol on human monocyte responses to TLR8 and TLR4 ligand stimulation and evaluated antiviral (Type I IFNs), pro- (TNF alpha) and anti-inflammatory (IL-10) cytokine production. Our novel data indicate that IFN $\beta$ production in response to TLR8 or TLR4 stimulation was significantly attenuated in monocytes exposed to alcohol. These data suggest that 

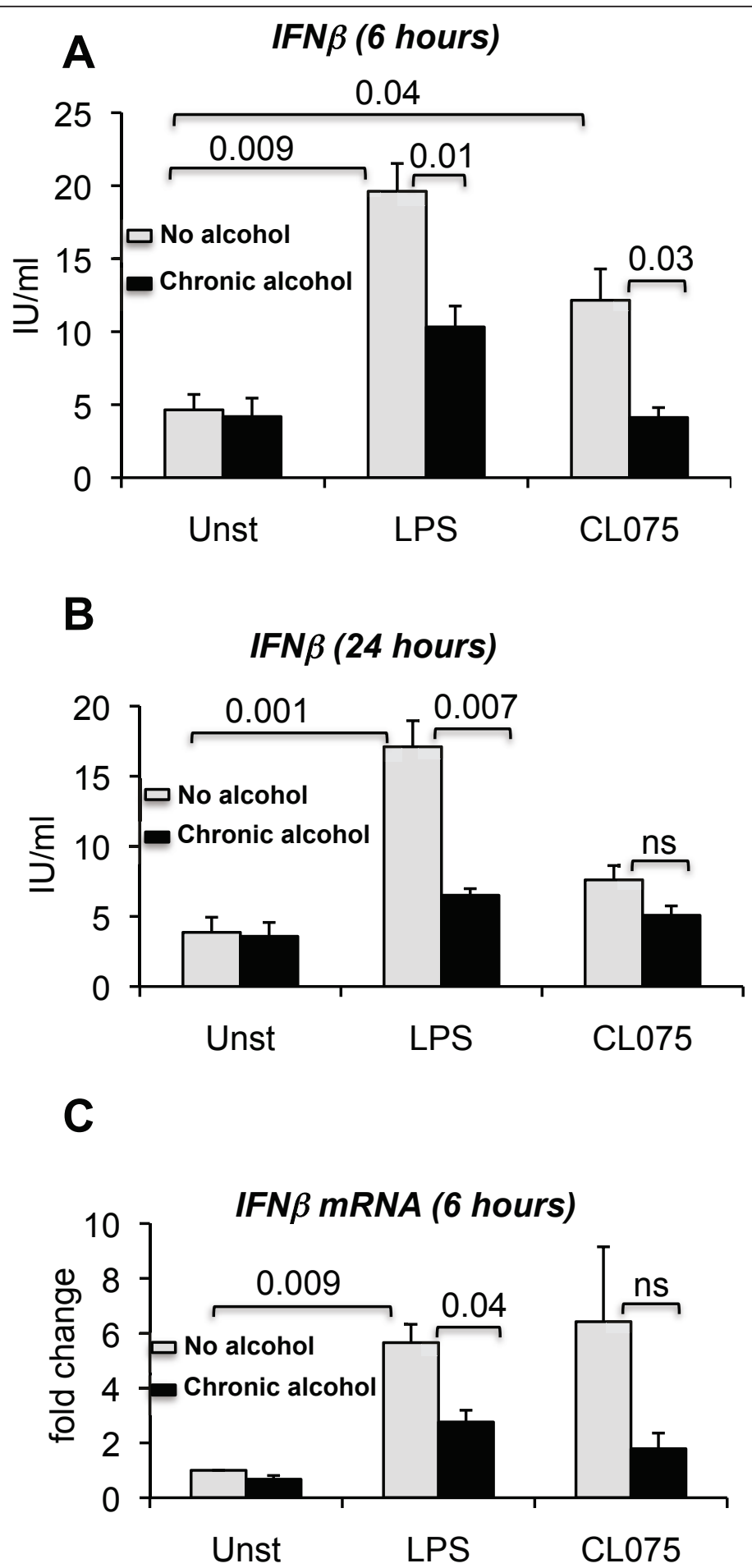

Figure 2 Prolonged alcohol exposure down regulates TLR8- or TLR4- induced IFN $\beta$ expression both at protein and mRNA levels. Human monocytes ( $n=5$ or 6 ) were either treated or not with $25 \mathrm{mM}$ ethanol for 7 days, $2.5 \mathrm{ug} / \mathrm{ml}$ CL075 or 0.1 ug/ml LPS for 6 or 24 hours and alcohol treated cells were further stimulated or not with CLO75 or LPS for 6 hours (A and C) or 24 hours (B). The cell-free supernatants were collected and analyzed for IFN $\beta$ production by ELISA ( $A$ and $B, n=6$ ). Total RNA was extracted from the cells and real time PCR was performed to quantify the IFN $\beta$ gene expression $(C, n=5)$. Error bars represent \pm SEM. unst: unstimulated, ns: non significant. 


\section{TNF $\alpha$ (6 hours)}

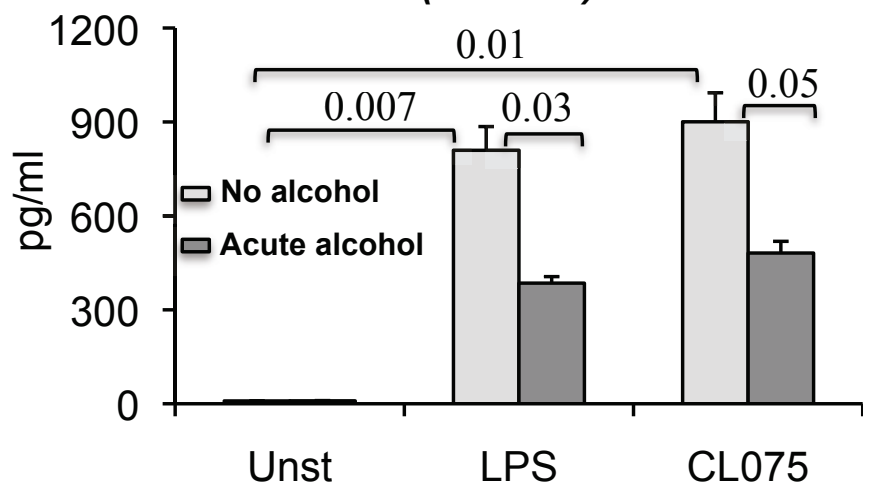

Figure 3 Acute alcohol treatment down regulates TLR8- or TLR4- induced TNF alpha production. Human monocytes ( $\mathrm{A}=3$ ) were either treated or not with $25 \mathrm{mM}$ ethanol or $2.5 \mathrm{ug} / \mathrm{ml} \mathrm{CLO75}$ (TLR8 ligand) or $0.1 \mathrm{ug} / \mathrm{ml}$ LPS (TLR4 ligand) for 6 hours. Some cells were stimulated with a combination of $25 \mathrm{mM}$ ethanol and $2.5 \mathrm{ug} / \mathrm{ml}$ CLO75 or $25 \mathrm{mM}$ ethanol and $0.1 \mathrm{ug} / \mathrm{ml}$ LPS. The cell-free supernatants were collected and TNF alpha production was measured by ELISA. Error bars represent \pm SEM. unst: unstimulated.

alcohol, regardless of the length of exposure, has inhibitory effects on Type I IFN production in monocytes. Our data further demonstrate that the effects of prolonged alcohol are opposite on Type I IFN induction and inflammatory cytokine induction within the same cell type. Prolonged alcohol exposure inhibited IFN $\beta$ production while it increased TLR8- and TLR4-induced TNF alpha production. Finally, we show that the previously described anti-inflammatory effect of acute alcohol on TNF alpha production extends to TLR8-induced TNF alpha induction and involves simultaneous induction of the anti-inflammatory cytokine, IL-10, in human monocytes.

Toll-like receptors are evolutionarily preserved receptors for recognition of danger signals [37]. Nucleic acid sequences in viruses are recognized by TLRs expressed in the endosome including TLR7 and TLR8 that sense single-stranded RNA and TLR9 that sense bacterial DNA [27]. LPS, a component of gram-negative bacteria, activates TLR4 expressed on the cell surface [27]. Human monocytes express a broad repertoire of functionally active TLRs including TLR8 and TLR4 [9,27]. We found that TLR8 or TLR4 ligand stimulation resulted in the induction of both IFN $\beta$ and inflammatory cytokines in human blood monocytes. Ligand activation of TLR8 recruits MyD88, a common TLR adapter, and triggers activation of IRAK1/4 kinases and the TRAF6/TAK1 complex leading to the activation of the IKK kinase complex that in turn induces inflammatory cytokines, TNF alpha or IL-10 or phosphorylation of IRFs that induce production of Type I IFNs [38]. TLR4 signaling involves recruitment of the adaptor molecules MyD88 and/or TRIF, each activating different downstream pathways to induce inflammatory cytokines via NF- $\kappa$ B or Type I IFNs via IRF activation, respectively
[38]. Considering the differences between the TLR8- and TLR4-induced signaling, our data suggest that alcohol likely modulates multiple components of these signal transduction pathways. Indeed, modulation of NF- $\kappa \mathrm{B}$ by acute and chronic alcohol has been extensively studied in the past in LPS-stimulated monocytes [28,39].

The inhibitory effect of alcohol on Type I IFN induction is likely to be a clinically significant finding considering the large number of studies that demonstrate a clinical correlation between alcohol use and impaired anti-viral immune mechanisms $[3,17,18,40,41]$. Excessive alcohol consumption is known to predispose individuals to secondary infections such as HCV, HIV and bacterial infections $[5-7,20]$. We found that the inhibitory effects of alcohol occurred both at the IFN $\beta$ protein and mRNA levels. As we found no significant changes in TLR8 and TLR4 mRNA or protein after alcohol treatment, we speculate that alcohol interferes with some of the intracellular signaling elements required for IFN $\beta$ gene induction in monocytes. Recently, Zhao et al have described the role of PPAR-gamma in limiting IFN $\beta$ production via targeting IRF3 in macrophages [42]. In line with this report, alcohol has been shown to activate PPAR-gamma in rats [43] and mice [44].

Previous studies from our and other laboratories showed that IFN-induced signaling pathways are also inhibited by alcohol in blood monocytes as well as in liver cells [19,39,45-47]. Phosphorylation of STAT-1 and STAT-3 was inhibited by acute alcohol suggesting not only IFN $\beta$ production but even Type I IFN-induced downstream events could be impaired by alcohol exposure [39]. Recently, we showed that chronic alcohol upregulates microRNA (miRNA)-155 in macrophages [48] therefore, it is reasonable to argue that alcohol might be targeting other miRNAs to limit IFN $\beta$ 

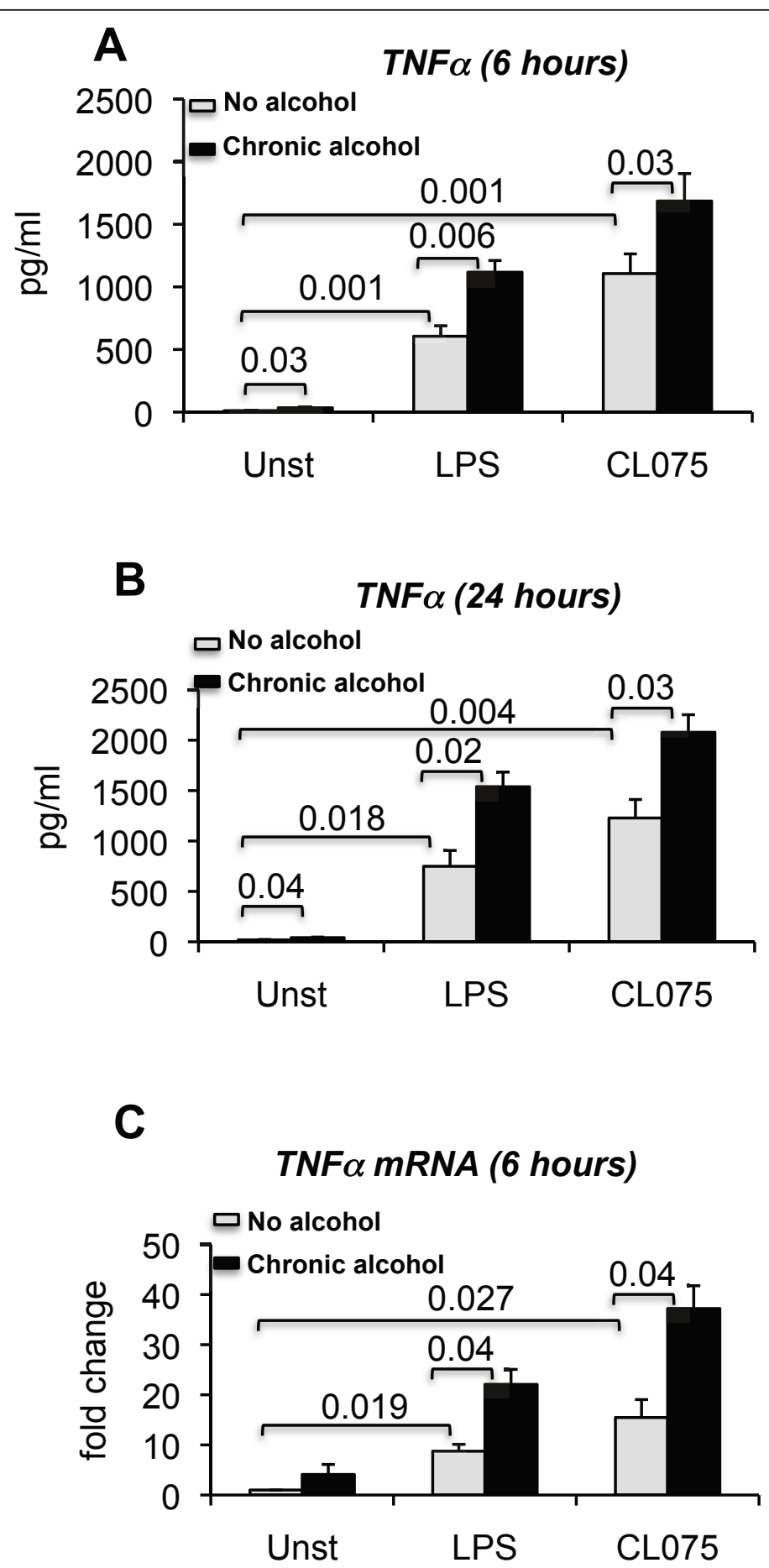

Figure 4 Prolonged alcohol exposure augments TLR8 or TLR4 induced TNF alpha expression. Human monocytes $(n=6$ or 7$)$ were either

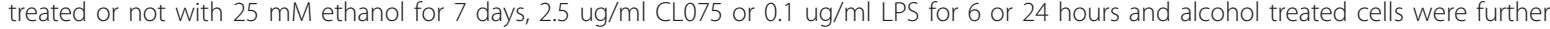
stimulated or not with CL075 or LPS for 6 hours (A and C) or 24 hours (B). The cell-free supernatants were collected and analyzed for TNF alpha production by ELISA ( $A$ and $B, n=6$ ). RNA was extracted from the cells and real time PCR was performed to quantify TNF alpha gene expression $(C, n=5)$. Error bars represent \pm SEM. unst: unstimulated. 


\section{IL-10 (6 hours)}

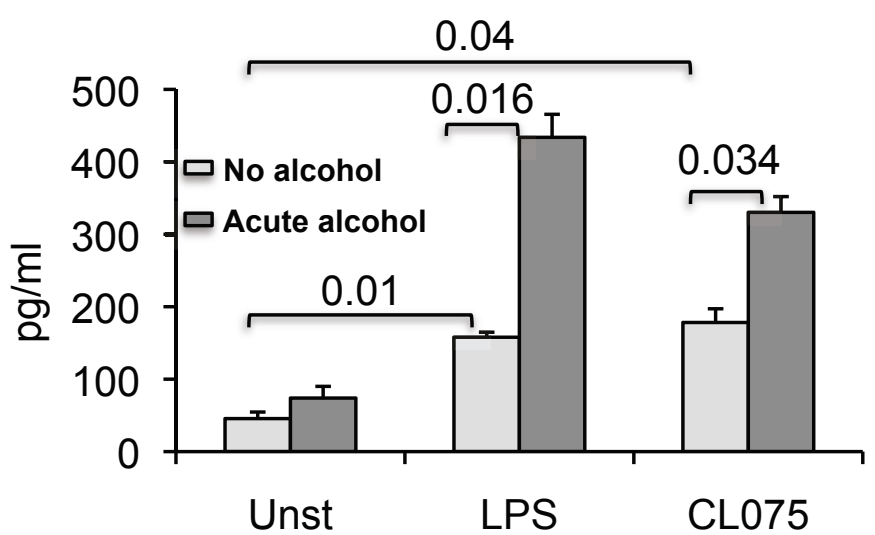

Figure 5 Acute alcohol exposure augments TLR8- or TLR4- induced IL-10 expression. Human monocytes ( $\mathrm{n}=3$ ) were either treated or not with $25 \mathrm{mM}$ ethanol or $2.5 \mathrm{ug} / \mathrm{ml} \mathrm{CL075}$ (TLR8 ligand) or $0.1 \mathrm{ug} / \mathrm{ml}$ LPS (TLR4 ligand) for 6 hours. Some cells were stimulated with a combination of $25 \mathrm{mM}$ ethanol and $2.5 \mathrm{ug} / \mathrm{ml}$ CL075 or $25 \mathrm{mM}$ ethanol and $0.1 \mathrm{ug} / \mathrm{ml}$ LPS. The cell-free culture supernatants were collected and IL-10 production was measured by ELISA. Error bars represent \pm SEM. unst: unstimulated.

production. In fact, miR-26a, $-34 \mathrm{a},-145$, and let-7b are shown to directly regulate IFN $\beta$ in human and macaque cells [49].

We found that acute and prolonged alcohol had opposite effects on both TLR8- and TLR4-induced TNF alpha production in human monocytes. Our laboratory has extensively studied the opposite effects of acute and prolonged alcohol on TLR4-mediated signaling pathways and identified IRAK-M, IRAK1, IKK phosphorylation and NF- $\kappa \mathrm{B}$ activation as common targets of acute and chronic alcohol with opposite effects.

We showed that the inhibitory effects of acute alcohol are mediated by alcohol- induced inhibition of NF- $\kappa \mathrm{B}$ activation due to decreased phosphorylation of IKK $\alpha$ and IKK $\beta$ in LPS-stimulated human monocytes [50]. Based on this information and the fact that TNF alpha induction involves NF- $\kappa \mathrm{B}$ activation whether induced via TLR8 or TLR4, our observation of decreased TNF alpha in acute alcohol-exposed TLR8 stimulated monocytes suggests that NF- $\kappa \mathrm{B}$ inhibition is a likely mechanism for inhibition of TLR8- induced TNF alpha induction by acute alcohol. An additional mechanism that likely contributes to decreased TNF alpha production after acute alcohol is the increased induction of IL10 observed in TLR8 or TLR4 stimulated alcoholexposed monocytes in our experiments. The increased TNF alpha induction by TLR8 ligand in chronic alcohol-exposed monocytes might involve NF- $\kappa \mathrm{B}$ activation and reduced IRAK-M by chronic alcohol is also permissive to increase TNF alpha production [28]. Finally, induction of miR-155 after chronic alcohol treatment results in increased TNF alpha production via increasing TNF alpha mRNA stability [48], which is likely the mechanism not only for TLR4- but also TLR8-induced TNF alpha production in monocytes.

Lastly, alcohol treatment (acute or chronic) modulates cytokines that negatively regulate TNF alpha. Previous studies from our laboratory demonstrated that acute alcohol increases IL-10, TGF $\beta$ and IL-13 production in human monocytes [51-53]. In a mouse model, acute alcohol has been shown to inhibit TLR-induced inflammatory responses via the p38 and ERK1/2 pathway [54]. While our or others studies found no obvious decrease in the level of anti-inflammatory cytokines after prolonged alcohol exposure in monocytes or in vivo, there is an obvious imbalance between pro- and anti-inflammatory cytokines with the presence of increased TNF alpha and no increase in IL-10 in human monocytes after prolonged alcohol treatment. Thus, it is possible that prolonged alcohol exposure targets multiple signaling molecules to augment TNF alpha expression.

\section{Conclusions}

In summary, to our best knowledge, our data show for the first time that alcohol modulates TLR8-induced monocyte functions both at the level of anti-viral and inflammatory mediator production. Our observations suggest that alcohol exposure, whether acute or prolonged, impairs Type I IFN responses to viral and bacterial PAMPs. The reduced Type I IFN production occurs in the face of increased pro-inflammatory (TNF alpha) cytokine production in monocytes with chronic alcohol exposure suggesting that prolonged alcohol changes the immune balance of monocyte activation. 

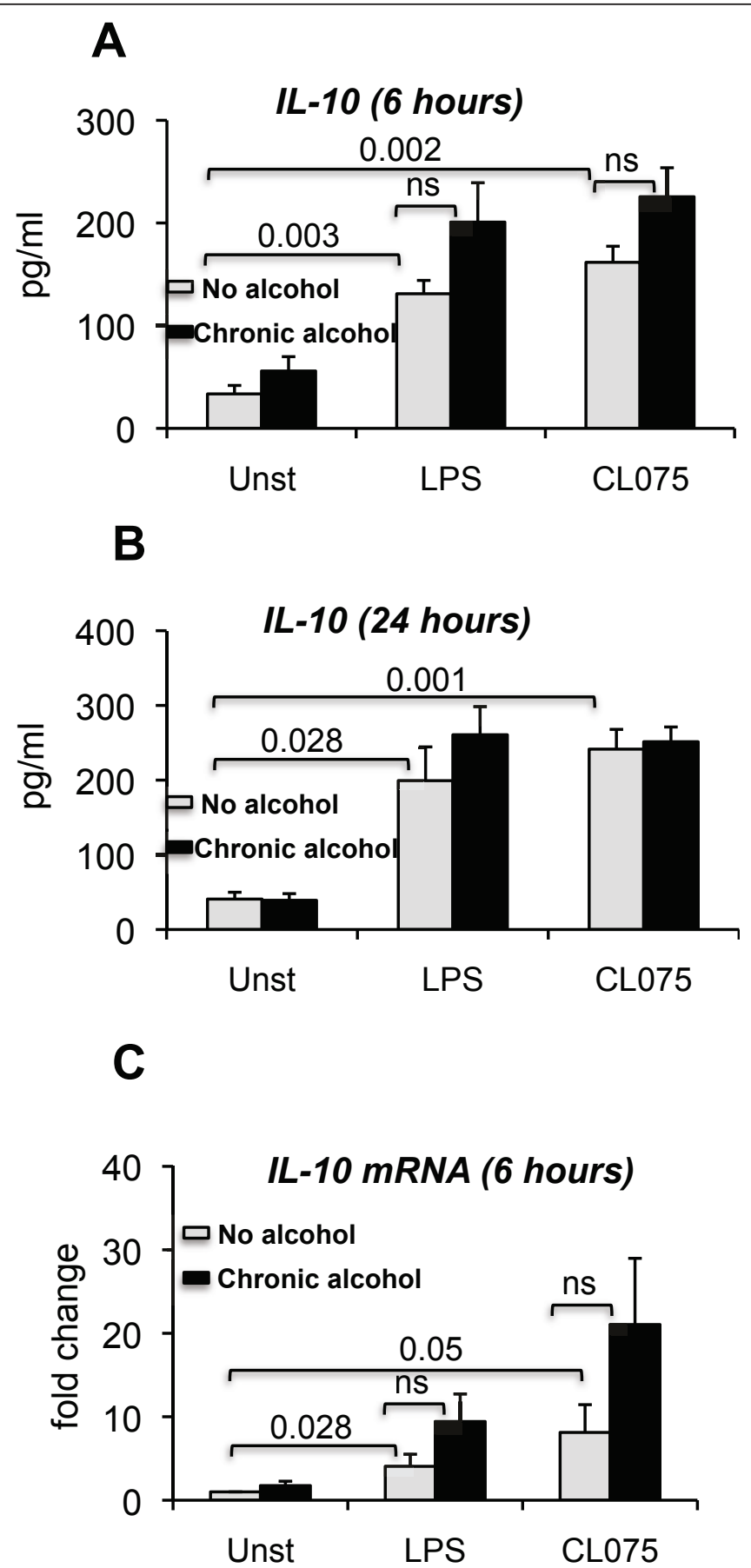

Figure 6 No significant changes in IL-10 expression after prolonged alcohol treatment. Human monocytes $(n=6$ or 7$)$ were either

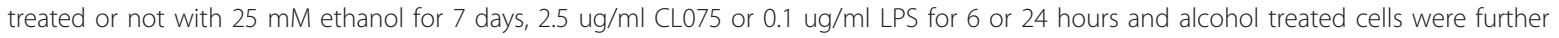
stimulated or not with CL075 or LPS for 6 hours (A and C) or 24 hours (B). The cell free supernatants were collected and analyzed for IL-10 alpha production by ELISA ( $A$ and $B, n=6$ or 7). RNA was extracted from the cells and real time PCR was performed to quantify IL-10 gene expression $(C, n=5)$. Error bars represent \pm SEM. unst: unstimulated. ns: non significant.

\section{Methods}

Human monocyte isolation and reagents

Blood was collected from healthy individuals and monocytes were isolated by the adherence method as described previously [28]. The selection criteria for the individuals signed up for this study was the same as mentioned in our previous study [28] and is approved by the "Institutional Review Board" (IRB), which is 
called the "Committee for the Protection of Human Subjects in Research" at UMMS. LPS and CL075 were purchased from Sigma-Aldrich and Invivogen respectively. Of note, CL075 mainly induces TLR8, however at high concentrations it can also induce TLR7. The possibility of TLR7 induction in our study is very minimal as monocytes mainly express TLR8 and the concentration of CL075 that we have used in our experiments is very low. Elisa kits for IFN $\beta$ (cat \# GL80905), TNF alpha (cat \# 555212) and IL-10 (Cat \# 88-7106) were purchased from Fujirebio Inc, BD Biosciences and eBioscience respectively.

\section{Cells stimulation}

The cells were cultured in 10\% IMDM with MEM supplements at $1 \times 10^{6} \mathrm{cell} / \mathrm{ml}$. The serum was obtained from HyClone and its endotoxin level was less than 0.06 $\mathrm{EU} / \mathrm{ml}$. Cells were stimulated with $25 \mathrm{mM}$ ethanol for 6 hours (acute) or for 7 days (prolonged) and later challenged or not with $2.5 \mathrm{ug} / \mathrm{ml} \mathrm{CL075}$ or $0.1 \mathrm{ug} / \mathrm{ml}$ LPS for 6 hours or 24 hours as indicated in the figure legends. For prolonged alcohol treatment (7 days), the cells were incubated in a C.B.S. Scientific chamber with double the alcohol concentration in the bottom of the chamber (to saturate the chamber) and on day 3 or 5 , half of the medium was replaced with fresh medium containing alcohol as described previously [28].

Alcohol concentration in the cell-free supernatants was assessed using the Analox Alcohol Analyzer (Analox Instruments).

\section{Cell viability}

Cell viability was checked with an MTT assay (Promega) as per manufacturer's recommendations. Briefly, cells at $1 \times 10^{6}$ cells $/ \mathrm{ml}$ were grown in a 96 well plate and treated or not with $25 \mathrm{mM}$ alcohol for indicated times. 15 $\mu \mathrm{l}$ of MTT dye solution was added and incubated at $37^{\circ}$ $\mathrm{C}$ for $\sim 2$ hours in a humidified $5 \% \mathrm{CO}_{2}$ incubator. After incubation, $100 \mu \mathrm{l}$ of solubilization solution was added and the optical density was measured at 550nm with a reference wavelength of $650 \mathrm{~nm}$ in a microplate reader (Labsystems). The percentage cell viability was calculated as mean OD of treated cells/mean OD of nontreated cells $* 100$.

\section{RNA analysis}

RNA was isolated with the RNeasy mini kit (Qiagen) and cDNA synthesis was carried out using the QuantiTect transcription kit (Qiagen). The quality of isolated RNA was assessed by spectrophotometric method. Real time PCR was performed (Bio Rad's iCycler iQ real-time detection system) to quantify the expression levels of IFN $\beta$, TNF alpha and IL-10 using gene specific primers. The $\mathrm{Ct}$ values were normalized to $18 \mathrm{~s}$ (internal control) and fold change was calculated with reference to unstimulated cells. The primers were synthesized from IDT Inc (USA) and the specificity of each primer set was determined by melt curve analysis. The primer sequences were as follows: 18s, forward 5'-GTAAC CCGTTGAACCCCATT-3', reverse 5'-CCATCCAAT CGG TAGTAGCG-3'; TNF $\alpha$, forward 5'-ATCTTCTCGAACCCCGAGTGA-3', reverse 5' - CGGTTCAGCCACTGGAGCT-3', IL-10, forward 5'- AGACCCAGA CATCAAGGC GCA-3', reverse 5'-ATCGATGACAGCGCCGTAGCC-3', IFN $\beta$, forward 5'-TCATA TGCAGTACATTAGCCATCA -3', reverse 5'-GATCTC CTAGCCTGTGCCTC-3’.

\section{ELISA}

The amount of IFN $\beta$, TNF alpha and IL-10 in cell-free supernatants was measured by ELISA as per manufacturer's instructions.

\section{Flow cytometry analysis}

Isolated monocytes were rested for one day and next day either stimulated or not with $25 \mathrm{mM}$ alcohol for indicated times. At the end of stimulation, cells were used for staining using standard staining methods. Briefly, cells were collected, washed and incubated with fluorochrome-conjugated TLR4 (Biolegend, cat\# 312805) and CD 14 or isotype control Abs at $4^{\circ} \mathrm{C}$ for $30 \mathrm{~min}$, washed twice in PBS containing 2\% FBS and fixed in 1\% paraformaldehyde. For TLR8 staining, cells were first stained for cell surface CD14 protein and then permeabilized using a cell permeabilization kit (BD biosciences), and incubated with TLR8 Ab (Imgenex, cat\# IMG321C) and later fixed. Data was collected using a FACScan II flow cytometer (BD Biosciences), and analyzed using FlowJo software (Tree Star, Inc.). The fluorochrome-conjugated Abs against human cell surface protein CD14 (cat\# 555399) and isotype controls were purchased from BD Pharmingen.

\section{Statistical analysis}

Statistical analysis was carried out by student $\mathrm{t}$ test (two tailed) and $\mathrm{p}$ value less than 0.05 was considered significant.

\section{Additional material}

Additional file 1: Table S1. Alcohol concentration in the supernatants of cultured human monocytes.

Additional file 2: Figure S1. Alcohol treatment does not affect cell viability. Human monocytes $(n=2)$ were either treated or not with 25 $\mathrm{mM}$ alcohol for indicated times in a 96 well plate at $1 \times 10^{6} \mathrm{cell} / \mathrm{ml}$. Cell viability was assessed by an MTT kit as per manufacture's instruction and optical density was measured at $550 \mathrm{~nm}$ with a reference wavelength of $650 \mathrm{~nm}$. The percentage cell viability was calculated as mean OD of 
treated cells/mean OD of non-treated cells *100. Error bars represent mean \pm SEM. unst: unstimulated, ns: non significant.

Additional file 3: Table S2. Flow cytometric analysis of TLR4 and TLR8 proteins.

\section{Acknowledgements}

This work is supported by NIAAA grants AA008577 and AA011576 to GS.

\section{Author details}

'Department of Medicine, University of Massachusetts Medical School, 364 Plantation Street, Worcester, MA 01605, USA. ²Department of Medicine, Brown University School of Medicine, Rhode Island Hospital, Providence, Rhode Island 02903, USA.

\section{Authors' contributions}

GS and SB conceived the idea and outlined the project. MP, DC and KK carried out the experiments. GS, SB, DC and KK contributed to data analysis, writing and editing of the manuscript. All the authors read and approved the final manuscript.

Received: 7 April 2011 Accepted: 30 September 2011 Published: 30 September 2011

\section{References}

1. Bird MD, Choudhry MA, Molina PE, Kovacs EJ: Alcohol and trauma: a summary of the Satellite Symposium at the 30th Annual Meeting of the Shock Society. Alcohol 2009, 43:247-252.

2. Nath B, Li Y, Carroll JE, Szabo G, Tseng JF, Shah SA: Alcohol exposure as a risk factor for adverse outcomes in elective surgery. J Gastrointest Surg 2010, 14:1732-1741.

3. Szabo G, Aloman C, Polyak SJ, Weinman SA, Wands J, Zakhari S: Hepatitis C infection and alcohol use: A dangerous mix for the liver and antiviral immunity. Alcohol Clin Exp Res 2006, 30:709-719.

4. Szabo G, Mandrekar P: A recent perspective on alcohol, immunity, and host defense. Alcohol Clin Exp Res 2009, 33:220-232.

5. Safdar K, Schiff ER: Alcohol and hepatitis C. Semin Liver Dis 2004, 24:305-315.

6. Lederer SL, Walters KA, Proll S, Paeper B, Robinzon S, Boix L, Fausto N, Bruix J, Katze MG: Distinct cellular responses differentiating alcohol- and hepatitis C virus- induced liver cirrhosis. Virol J 2006, 3:98

7. Baum MK, Rafie C, Lai S, Sales S, Page JB, Campa A: Alcohol use accelerates HIV disease progression. AIDS Res Hum Retroviruses 2010, 26:511-518.

8. Samet JH, Cheng DM, Libman H, Nunes DP, Alperen JK, Saitz R: Alcohol consumption and HIV disease progression. J Acquir Immune Defic Syndr 2007, 46:194-199.

9. Koyama S, Ishii KJ, Coban C, Akira S: Innate immune response to viral infection. Cytokine 2008, 43:336-341.

10. Xagorari A, Chlichlia K: Toll-like receptors and viruses: induction of innate antiviral immune responses. Open Microbiol J 2008, 2:49-59.

11. Szabo G, Dolganiuc $A$ : Hepatitis $C$ and innate immunity: recent advances. Clin Liver Dis 2008, 12:675-92.

12. Liu BS, Groothuismink ZM, Janssen HL, Boonstra A: Role for IL-10 in inducing functional impairment of monocytes upon TLR4 ligation in patients with chronic HCV infections. J Leukoc Biol 2011, 89:981-988.

13. Mureith MW, Chang JJ, Lifson JD, Ndung'u T, Altfeld M: Exposure to HIV-1encoded Toll-like receptor 8 ligands enhances monocyte response to microbial encoded Toll-like receptor 2/4 ligands. AIDS 2010, 24:1841-1848.

14. Schlaepfer E, Speck RF: TLR8 Activates HIV from Latently Infected Cells of Myeloid-Monocytic Origin Directly via the MAPK Pathway and from Latently Infected CD4+ T Cells Indirectly via TNF-\{alpha\}. J Immunol 2011, 186:4314-4324.

15. Cros J, Cagnard N, Woollard K, Patey N, Zhang SY, Senechal B, Puel A, Biswas SK, Moshous D, Picard C, Jais JP, D'Cruz D, Casanova JL, Trouillet C, Geissmann F: Human CD14dim monocytes patrol and sense nucleic acids and viruses via TLR7 and TLR8 receptors. Immunity 2010, 33:375-386.
16. Geissler M, Gesien A, Wands JR: Inhibitory effects of chronic ethanol consumption on cellular immune responses to hepatitis $C$ virus core protein are reversed by genetic immunizations augmented with cytokine-expressing plasmids. J Immunol 1997, 159:5107-5113.

17. Szabo G, Wands JR, Eken A, Osna NA, Weinman SA, Machida K, Joe Wang $\mathrm{H}$ : Alcohol and hepatitis $\mathrm{C}$ virus-interactions in immune dysfunctions and liver damage. Alcohol Clin Exp Res 2010, 34:1675-1686.

18. McCartney EM, Beard MR: Impact of alcohol on hepatitis $C$ virus replication and interferon signaling. World J Gastroenterol 2010, 16:1337-1343.

19. Plumlee CR, Lazaro CA, Fausto N, Polyak SJ: Effect of ethanol on innate antiviral pathways and HCV replication in human liver cells. Virol J 2005 2:89.

20. Berzsenyi MD, Roberts SK, Preiss S, Woollard DJ, Beard MR, Skinner NA, Bowden DS, Visvanathan K: Hepatic TLR2 \& TLR4 expression correlates with hepatic inflammation and TNF-alpha in HCV \& HCV/HIV infection. J Viral Hepat 2010, 1365-2893.

21. Dolganiuc A, Norkina O, Kodys K, Catalano D, Bakis G, Marshall C, Mandrekar P, Szabo G: Viral and host factors induce macrophage activation and loss of toll-like receptor tolerance in chronic HCV infection. Gastroenterology 2007, 133:1627-1636.

22. Hritz I, Mandrekar P, Velayudham A, Catalano D, Dolganiuc A, Kodys K, KurtJones E, Szabo G: The critical role of toll-like receptor (TLR) 4 in alcoholic liver disease is independent of the common TLR adapter MyD88. In Hepatology. Volume 48. Baltimore, Md; 2008:1224-31.

23. Montserrat MD, Mercedes M, Maria-Jose S, Claudio RR, Alberto T, Antonio V, Ana A, Clotilde FG, Jose-Antonio GG: Bacterial translocation in HIVinfected patients with HCV cirrhosis: Implication in haemodynamic alterations and mortality. J Acquir Immune Defic Syndr 2011, 56:420-427.

24. Ancuta P, Kamat A, Kunstman KJ, Kim EY, Autissier P, Wurcel A, Zaman T, Stone D, Mefford M, Morgello S, Singer EJ, Wolinsky SM, Gabuzda D: Microbial translocation is associated with increased monocyte activation and dementia in AIDS patients. PLoS One 2008, 3:e2516

25. Fujimoto M, Uemura M, Nakatani Y, Tsujita S, Hoppo K, Tamagawa T, Kitano H, Kikukawa M, Ann T, Ishii Y, Kojima H, Sakurai S, Tanaka R, Namisaki T, Noguchi R, Higashino T, Kikuchi E, Nishimura K, Takaya A, Fukui H: Plasma endotoxin and serum cytokine levels in patients with alcoholic hepatitis: relation to severity of liver disturbance. Alcohol Clin Exp Res 2000, 24:48S-54S.

26. Szabo G, Bala S: Alcoholic liver disease and the gut-liver axis. World J Gastroenterol 2010, 16:1321-1329.

27. Kawai T, Akira S: The roles of TLRs, RLRs and NLRs in pathogen recognition. Int Immunol 2009, 21:317-337.

28. Mandrekar P, Bala S, Catalano D, Kodys K, Szabo G: The opposite effects of acute and chronic alcohol on lipopolysaccharide-induced inflammation are linked to IRAK-M in human monocytes. J Immunol 2009, 183:1320-7.

29. von Haefen C, Mei W, Menk M, Klemz R, Jones A, Wernecke KD, Spies CD: Ethanol changes gene expression of transcription factors and cytokine production of CD4+ T-cell subsets in PBMCs stimulated with LPS. Alcohol Clin Exp Res 2011, 35:621-631.

30. Mandrekar P, Catalano D, White B, Szabo G: Moderate alcohol intake in humans attenuates monocyte inflammatory responses: inhibition of nuclear regulatory factor kappa B and induction of interleukin 10. Alcohol Clin Exp Res 2006, 30:135-139.

31. D'Souza NB, Mandujano JF, Nelson S, Summer WR, Shellito JE: Alcohol ingestion impairs host defenses predisposing otherwise healthy mice to Pneumocystis carinii infection. Alcohol Clin Exp Res 1995, 19:1219-1225.

32. Zhao XJ, Marrero L, Song K, Oliver P, Chin SY, Simon H, Schurr JR, Zhang Z, Thoppil D, Lee S, Nelson S, Kolls JK: Acute alcohol inhibits TNF-alpha processing in human monocytes by inhibiting TNF/TNF-alpha-converting enzyme interactions in the cell membrane. J Immunol 2003, 170:2923-2931.

33. Cassatella MA Meda L, Bonora S, Ceska M, Constantin G: Interleukin 10 (IL10) inhibits the release of proinflammatory cytokines from human polymorphonuclear leukocytes. Evidence for an autocrine role of tumor necrosis factor and IL-1 beta in mediating the production of IL-8 triggered by lipopolysaccharide. J Exp Med 1993, 178:2207-2211.

34. Murdoch EL, Karavitis J, Deburghgraeve C, Ramirez L, Kovacs EJ: Prolonged chemokine expression and excessive neutrophil infiltration in the lungs of burn-injured mice exposed to ethanol and pulmonary infection. Shock 2011, 35:403-410. 
35. Hill DB, Barve S, Joshi-Barve S, McClain C: Increased monocyte nuclear factor- kappaB activation and tumor necrosis factor production in alcoholic hepatitis. J Lab Clin Med 2000, 135:387-395.

36. McClain CJ, Hill DB, Song Z, Deaciuc I, Barve S: Monocyte activation in alcoholic liver disease. Alcohol 2002, 27:53-61.

37. Medzhitov R, Preston-Hurlburt P, Janeway CA Jr: A human homologue of the Drosophila Toll protein signals activation of adaptive immunity. Nature 1997, 388:394-397.

38. Mandrekar P, Szabo G: Signalling pathways in alcohol-induced liver inflammation. J Hepatol 2009, 50:1258-1266.

39. Norkina O, Dolganiuc A, Catalano D, Kodys K, Mandrekar P, Syed A, Efros M, Szabo G: Acute alcohol intake induces SOCS1 and SOCS3 and inhibits cytokine- induced STAT1 and STAT3 signaling in human monocytes. Alcohol Clin Exp Res 2008, 32:1565-1573.

40. McCartney EM, Semendric L, Helbig K, Hinze S, Jones B, Weinman SA, Beard MR: Alcohol metabolism increases the replication of hepatitis $C$ virus and attenuates the antiviral action of interferon. J Infect Dis 2008, 198:1766-1775.

41. Szabo G: Pathogenic interactions between alcohol and hepatitis C. Curr Gastroenterol Rep 2003, 5:86-92.

42. Zhao W, Wang L, Zhang M, Wang P, Zhang L, Yuan C, Qi J, Qiao Y, Kuo PC, Gao C: Peroxisome proliferator-activated receptor gamma negatively regulates IFN-beta production in Toll-like receptor (TLR) 3- and TLR4stimulated macrophages by preventing interferon regulatory factor 3 binding to the IFN-beta promoter. J Biol Chem 2011, 286:5519-5528.

43. Luvizotto RA, Nascimento AF, Veeramachaneni S, Liu C, Wang XD: Chronic alcohol intake upregulates hepatic expression of carotenoid cleavage enzymes and PPAR in rats. J Nutr 2010, 140:1808-1814.

44. Shen Z, Liang X, Rogers CQ, Rideout D, You M: Involvement of adiponectin-SIRT1-AMPK signaling in the protective action of rosiglitazone against alcoholic fatty liver in mice. Am J Physiol Gastrointest Liver Physiol 2010, 298:G364-74.

45. Petrasek J, Dolganiuc A, Csak T, Nath B, Hritz I, Kodys K, Catalano D, KurtJones E, Mandrekar P, Szabo G: Interferon regulatory factor 3 and type I interferons are protective in alcoholic liver injury in mice by way of crosstalk of parenchymal and myeloid cells. Hepatology 2011, 53:649-660.

46. Pruett SB, Schwab C, Zheng Q, Fan R: Suppression of innate immunity by acute ethanol administration: a global perspective and a new mechanism beginning with inhibition of signaling through TLR3. J Immunol 2004, 173:2715-2724.

47. Ye L, Wang S, Wang X, Zhou Y, Li J, Persidsky Y, Ho W: Alcohol impairs interferon signaling and enhances full cycle hepatitis $C$ virus JFH-1 infection of human hepatocytes. Drug Alcohol Depend 2010, 112:107-116.

48. Bala S, Marcos M, Kodys K, Csak T, Catalano D, Mandrekar P, Szabo G: Upregulation of microRNA-155 in macrophages contributes to increased tumor necrosis factor $\{a \mid p h a\}$ (TNF\{alpha\}) production via increased mRNA half-life in alcoholic liver disease. J Biol Chem 2011, 286:1436-1444.

49. Witwer KW, Sisk JM, Gama L, Clements JE: MicroRNA regulation of IFNbeta protein expression: rapid and sensitive modulation of the innate immune response. J Immunol 2010, 184:2369-2376.

50. Mandrekar P, Jeliazkova V, Catalano D, Szabo G: Acute alcohol exposure exerts anti-inflammatory effects by inhibiting IkappaB kinase activity and p65 phosphorylation in human monocytes. J Immunol 2007, 178:7686-7693.

51. Norkina O, Dolganiuc A, Shapiro T, Kodys K, Mandrekar P, Szabo G: Acute alcohol activates STAT3, AP-1, and Sp-1 transcription factors via the family of Src kinases to promote IL-10 production in human monocytes. J Leukoc Biol 2007, 82:752-762.

52. Szabo G, Verma BK, Fogarasi M, Catalano DE: Induction of transforming growth factor-beta and prostaglandin E2 production by ethanol in human monocytes. J Leukoc Biol 1992, 52:602-610.

53. Szabo G, Mandrekar P, Dolganiuc A, Catalano D, Kodys K: Reduced alloreactive T-cell activation after alcohol intake is due to impaired monocyte accessory cell function and correlates with elevated IL-10, IL13, and decreased IFNgamma levels. Alcohol Clin Exp Res 2001, 25:1766-1772.

54. Goral J, Kovacs EJ: In Vivo Ethanol Exposure Down-Regulates TLR2-, TLR4, and TLR9-Mediated Macrophage Inflammatory Response by Limiting p38 and ERK1/2 Activation. J Immunol 2005, 174:456-463. doi:10.1186/1471-2172-12-55

Cite this article as: Pang et al:: Inhibition of TLR8- and TLR4-induced

Type I IFN induction by alcohol is different from its effects on inflammatory cytokine production in monocytes. BMC Immunology 2011 12:55.

\section{Submit your next manuscript to BioMed Central and take full advantage of:}

- Convenient online submission

- Thorough peer review

- No space constraints or color figure charges

- Immediate publication on acceptance

- Inclusion in PubMed, CAS, Scopus and Google Scholar

- Research which is freely available for redistribution 